\title{
Nutritional status and human milk intake of exclusively breast-fed infants at high altitude in La Paz, Bolivia
}

\author{
Noelia Urteaga $^{1 *}$, José Luis San Miguel ${ }^{1}$, Ana María Aguilar ${ }^{1}$, Maruska Muñoz ${ }^{1}$ and Christine Slater ${ }^{2}$ \\ ${ }^{1}$ Instituto de Investigación en Salud y Desarrollo (IINSAD), Facultad de Medicina de la Universidad Mayor de San Andres, \\ CP-212 La Paz, Bolivia \\ ${ }^{2}$ Formerly affiliated with the Division of Human Health, International Atomic Energy Agency, A-1400 Vienna, Austria \\ (Submitted 2 August 2017 - Final revision received 6 December 2017 - Accepted 13 February 2018)
}

\begin{abstract}
Breast-feeding habits are related to the nutritional status and the risk of illness and death in children under 2 years of age. For the first 6 months, infants should be exclusively breast-fed. This study aimed to evaluate the relationship between the infant's nutritional status and human milk intake by breast-fed infants at high altitude. A quantitative, descriptive, correlational study was conducted including mother/baby pairs of infants aged 2-6 months. The amount of human milk consumed by the infants was assessed by the deuterium oxide dose-to-mother technique. The lipid content of human milk was measured by creamatocrit, and anthropometric measurements were performed. A total of eighteen mother/baby pairs were assessed. The mean human milk intake was 888 (sD 149) $\mathrm{g} / \mathrm{d}$, and the intake of water from other sources was 24.3 (SD 29.8) g/d. The lipid content in human milk was 41 (SD 12) g/l. The infant's nutritional indicators were normal in all cases. A moderate positive correlation was found between milk volume and $z$ scores weight-for-length $r 0.58(P=0 \cdot 01)$, BMI-for-age $r 0.56(P=0 \cdot 01)$ and weightfor-age $r 0.45(P=0.05)$. There was no correlation with length-for-age $z$ score. The mean of breast milk intake in this study was similar to that found in other studies in the world. The lipid content is comparable to similar studies and was within the normal range. Children older than 3 months showed signs of stunting despite adequate volume and lipid content of breast milk.
\end{abstract}

Key words: ${ }^{2}$ H: Human milk intake: Creamatocrit: Infants: High altitude

Feeding patterns of children influence their nutritional status, which determines their potential for growth and development. The practice of breast-feeding provides infants with adequate nutrients and immunity from a large number of infections and allergies $^{(1,2)}$. Breast-feeding habits are closely related to the risk of illness and death in children under the age of 2 years; they reduce the incidence of common infections such as diarrhoea, otitis media and pneumonia ${ }^{(3)}$, and are frequently associated with a decrease in the incidence of childhood diabetes, coeliac disease, Crohn's disease and other pathologies ${ }^{(4)}$. The WHO recommends exclusive breast-feeding of children for the first 6 months of life, and continued breast-feeding for up to 2 years ${ }^{(5)}$.

Data on breast-feeding habits are usually subjective and based on information reported by the mother. The traditional method for evaluation of the quantity of human milk consumed by breast-fed infants is test weighing, where the infant is weighed before and after each feed for several days, but this method is difficult to perform, and can disturb the normal feeding pattern. In 1979, Coward et al. introduced the deuterium oxide dose-to-mother technique, a non-invasive isotope method that does not disturb the normal feeding pattern, and has the advantage in field studies of providing information on the exclusivity of breast-feeding, as well as the volume of milk consumed by breast-fed infants ${ }^{(6)}$. In this method, the mother consumes a known amount of deuterium oxide: water labelled with ${ }^{2} \mathrm{H}$, a stable isotope of $\mathrm{H}$. The ${ }^{2} \mathrm{H}$ equilibrates with her body water within a few hours. The infant consumes ${ }^{2} \mathrm{H}$ during breast-feeding. If saliva samples are collected from the mother and her infant over a 2-week period, the quantity of human milk ingested by the infant can be calculated and also the amount of water derived from sources other than human milk (i.e. other fluids and complementary foods) ${ }^{(7-9)}$.

The lipid content of human milk is an important contributor to the energy content, and the most variable macronutrient component. The lipid concentration can be quickly and easily estimated in low-resource settings by measuring the creamatocrit ${ }^{(10)}$. The linear relationship between the calculated energy value and the creamatocrit is owing to the relative constancy of the energy contribution of protein and lactose in human milk ${ }^{(10,11)}$.

In Bolivia, $60 \%$ of infants are exclusively breast-fed for 6 months as reported by the National Demographic Health

Abbreviation: LAZ, length-for-age $z$ score.

* Corresponding author: N. Urteaga, fax +5912 2246550, email noelia.urteaga@gmail.com 
Survey $^{(12)}$, which reports exclusive breast-feeding based in a questionnaire applied to the mother with respect to the last baby born in the previous 5 years. This is one of the highest rates of exclusive breast-feeding in Latin America ${ }^{(13)}$. At 1 year of age, at least $84 \%$ of infants are breast-feeding with complementary feeding. At 6 months of age, 3.9\% of infants are stunted, but this increases to $16 \%$ by the end of the 1 st year, and to $25 \%$ by the child's second birthday ${ }^{(12)}$. In a systematic review of energy consumption of exclusively breast-fed infants aged 3-6 months, Reilly et al., in longitudinal studies, found that breast milk transfer from mother to baby in exclusively breast-fed infants does not change with age from 3 to 6 months, and most described the pattern of change in intake over time as a 'plateau' in milk transfer after 3 months ${ }^{(14)}$. Recommendations based on energy expenditure plus energy needs for growth assume that the energy intake of infants is self-regulated and matches energy needs ${ }^{(15)}$

The aim of this study was to evaluate the relationship between infants' nutritional status and the volume, and lipid content of human milk consumed by breast-fed infants in Bolivia.

\section{Methods}

A quantitative, observational, cross-sectional study was conducted including mothers and their infants between 2 and 6 months of age, living in peri-urban areas of La Paz city, Bolivia. This study was reviewed and approved by the Research Ethic Commission of National Bioethical Committee (CEI-CNB) of Bolivia. All study participants provided individual informed consent. Exclusively breast-fed infants born at term with appropriate weight for gestational age were included. Exclusion criteria included mothers with lactation difficulties (e.g. mastitis), taking medications and acute illness of the mother or child during the period of the protocol.

A convenience sample was recruited from mothers attending educational meetings at the Center for Popular Culture (CCP). A total of eighteen mother/baby pairs were evaluated. The infants were divided into two groups for assessment of growth faltering: infants in group 1 were under $120 \mathrm{~d}$ old and those in group 2 over $120 \mathrm{~d}$ old, according to Simondon et al. ${ }^{(16)}$ and Victora et $a l^{(17)}$ considerations.

\section{Anthropometry}

Infants were weighed without clothes to the nearest $\pm 0.01 \mathrm{~kg}$ using a paediatric electronic scale (Seca 745; SECA Deutschland). The length of the child was measured to the nearest $\pm 0 \cdot 2 \mathrm{~cm}$ using a calibrated mobile baby measuring mat (Seca 417; SECA Deutschland). $z$ Scores were calculated using the WHO ANTHRO 3.0 software.

Mothers were weighed without shoes but with minimal clothes using an electronic scale accurate to $0 \cdot 1 \mathrm{~kg}$ (Seca 882; SECA Deutschland). Maternal height was measured to the nearest $\mathrm{mm}$ using a portable stadiometer (Seca 217; SECA Deutschland).

\section{Measurements of human milk intake}

Human milk intake was measured using the dose-to-the-mother deuterium-oxide turnover technique (protocol International Atomic Energy Agency (IAEA), 2010) ${ }^{(8)}$. On the 1st day of the study (day 0), mothers and their infants came to the institute for anthropometry measurements and administration of the dose of deuterium oxide to the mothers. The weight of the mother and her infant was measured before the dose of deuterium oxide was given to the mother. The infant was also weighed at the end of the protocol at the institute (day 14).

\section{${ }^{2} \mathrm{H}$ dose administration and collection of saliva samples}

Deuterium oxide (99.8\%, sterility tested) was obtained from Sercon Ltd. Each mother received an accurately weighed dose of $30 \mathrm{~g}$ of deuterium oxide.

Baseline samples of saliva were collected from the mother and her baby before administration of the dose. A researcher (N. U.) visited the mothers' home to collect further saliva samples from mothers and babies 1, 2, 3, 4, 13 and $14 \mathrm{~d}$ after dose administration. Saliva samples were collected at least $30 \mathrm{~min}$ after the last meal in the mothers, and at least 15 min after the last feed in the infants. All samples were transported to the laboratory and stored $-20^{\circ} \mathrm{C}$ until analysis.

\section{Analysis of ${ }^{2} \mathrm{H}$ enrichment and calculation of human milk intake}

The ${ }^{2} \mathrm{H}$ enrichment of saliva samples was determined using a Fourier transform infrared (FTIR) spectrometer (model 4100; JASCO International Co. Ltd.), as described in the protocol provided by IAEA ${ }^{(8)}$.

Data were fitted to the model described by Haisma et al., using a spreadsheet template that was downloaded from the IAEA Human Health Campus (https://nucleus.iaea.org/HHW/ Nutrition/MilkIntake/index.html). The spreadsheet uses the 'Solver' add-in of Microsoft Excel to fit the model to the data using the method of least squares (Fig. 1). The total error is a measure of how well the modelled curves fit the data, and is the square root of the total mean square error for the mother and her infant. A total error of $<60$ is considered acceptable, when ${ }^{2} \mathrm{H}$ enrichment is measured by FTIR spectrometry ${ }^{(18)}$.

\section{Lipid content of human milk}

Freshly expressed small mid-feed samples $(5-10 \mathrm{ml})$ of human milk were collected by mothers at home, 3-5 min after the onset of nursing from one breast ${ }^{(19)}$, three times in $1 \mathrm{~d}$ (morning, afternoon and night). Each milk sample was mixed well and divided into two aliquots. The first aliquot was analysed, and a second aliquot was mixed with the other two samples before analysis. All samples were analysed within $24 \mathrm{~h}$ of collection.

A micro-centrifuge (model $\mathrm{CH} 24$; Rolco SRL), glass capillary tubes and a microhematocrit reader were used. Milk was drawn by capillarity into microhaematocrit tubes from a well-mixed sample. The tubes were sealed at one end with clay (Critoseal) and centrifuged at $12000 \mathrm{rpm}$ for $15 \mathrm{~min}$. The cream column separated from milk by centrifugation was measured with the microhematocrit reader. The creamatocrit was determined from the length of this cream column and expressed as a percentage of the length of the total milk column. All creamatocrit measurements were recorded three times and the averaged values 
were used for data analysis. Lipid content was calculated from the creamatocrit using the following equation ${ }^{(10)}$ :

$$
\operatorname{Milkfat}(\mathrm{g} / \mathrm{l})=(\% \text { cream }-0.59) / 0 \cdot 146
$$

The energy content of human milk was estimated using the following equation $^{(10)}$ :

$$
\mathrm{kcal}=(290+668) \times \% \text { cream } .
$$

\section{Statistical analysis}

Statistical analysis was performed using SPSS 18.5 for windows (SPSS Inc.). The results are quoted as means and standard deviations. A Shapiro-Wilk $W$ normality test was performed. Independent two-sample $t$ tests were used to assess the significance of the difference between means. Significance was determined at the $95 \%$ confidence level $(P<0 \cdot 05)$. MannWhitney $U$ test and Wilcoxon's tests were used to determine difference between two independent small samples that were not normally distributed. The linear correlation between variables was determined using Pearson's correlation coefficient $(r)$.

\section{Results}

All variables, except length-for-age $z$ score (LAZ), were normally distributed based on the Shapiro-Wilk $W$ normality test $(>0.90)$. A total of eighteen mother/baby pairs were included in the analysis; the maternal age was 28.8 (SD 5.9) years and infant's age was 3.1 (SD 1.6) months, and in the younger group the mean age was $2 \cdot 2(\mathrm{SD} 0 \cdot 4)$ and in the older group it was 5 (SD 0.8) months.

\section{Anthropometric characteristics}

The anthropometric characteristics of the mothers and infants are summarised in Table 1. Mothers' BMI was $25 \cdot 7$ (SD 4.5) (19.7 to $35 \cdot 8)$. According to the WHO classification ${ }^{(20)}$, the nutritional status of $50 \%$ of mothers is considered adequate: $17 \%$ were overweight and $33 \%$ obese.

Infants' weight-for-length $z$ score was $0 \cdot 2$ (SD $0 \cdot 7)(17 / 18$ between -1 and $+1,1 / 18>+1$ ) and BMI-for-age $z$ score was 0.04 (SD 0.7), and thus none of the infants were malnourished. The mean LAZ was -0.6 (SD 0.9) (7/18 between -2 and $-1,10$ / 18 between -1 and +1 and $1 / 18>+1)$ for all infants.
In infants younger than $120 \mathrm{~d}$, LAZ was -0.3 (SD 0.7 ) $(1 / 9<-1,4 / 9$ between -1 and $0,4 / 9$ between 0 and +1$)$, and in infants older than $120 \mathrm{~d}$ it was -0.8 (SD 1.1) (6/9 between -2 and $-1,2 / 9$ between -1 and 0 and $1 / 9>+1$ ). This is illustrated in the box plot in Fig. 2. In the younger group, one infant was mildly stunted (LAZ $<-1$ ), but in the older group 6 infants had LAZ $<-1$. Because of the small group size, LAZ was not normally distributed, and thus we decided to use non-parametric statistics, finding a significant difference $(P=0.009)$, with the older group showing signs of growth faltering.

\section{Human milk intake}

Fig. 1 shows an example of the enrichment of ${ }^{2} \mathrm{H}$ in the saliva of a mother and her infant. The ${ }^{2} \mathrm{H}$ gradually disappears from the mother's body and appears in the infant's saliva after breast-feeding, reaching a maximum after about $5 \mathrm{~d}$ before returning to the background levels. The mean amount of human milk consumed by the infants was 888 (SD 149) g/d $(656-1211 \mathrm{~g} / \mathrm{d})$. The intake of water from other sources (non-human milk liquids and complementary foods) was $24 \cdot 3$ (SD 29.8) g/d, showing that the infants were exclusively or predominantly breast-fed according to the Haisma study ${ }^{(9)}$, in which exclusively breast-fed infants received $0-24 \mathrm{~g} / \mathrm{d}$ of non-breast milk water, and predominantly breast-fed infants received 53-216 g non-breast milk water per d. Studies in Guatemala $^{(21)}$ and Cameroon ${ }^{(22)}$ used $52 \mathrm{~g} / \mathrm{d}$ of non-breast milk water as the cut-off for exclusive breastfeeding. There were no significant differences between age groups and sex (Table 2).

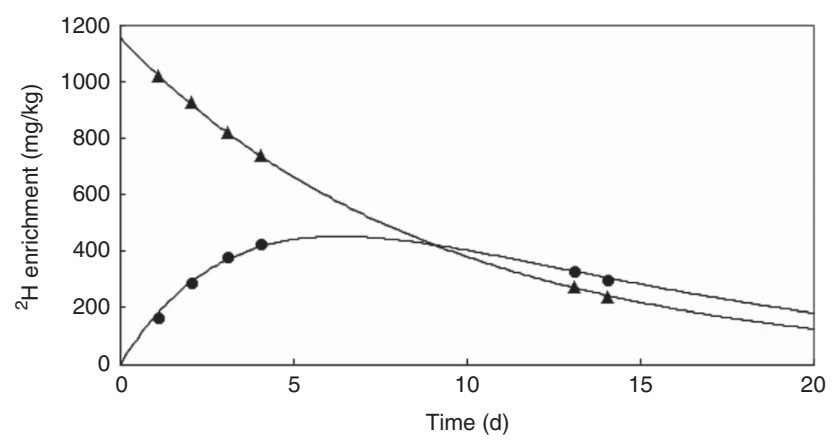

Fig. 1. $z$ Score length/age by age groups.

Table 1. Mother/baby pairs anthropometric characteristics

\begin{tabular}{|c|c|c|c|c|c|c|c|c|c|c|}
\hline & \multicolumn{2}{|c|}{ Total $(n 18)$} & \multicolumn{4}{|c|}{ Groups by infant's age ( $\leq 120 \mathrm{~d}, n 9>120 \mathrm{~d}, n 9)$} & \multicolumn{4}{|c|}{ Groups by infant's sex (female, $n 6$; male, $n$ 12) } \\
\hline & Mean & SD & Mean & SD & Mean & SD & Mean & SD & Mean & SD \\
\hline Mother's weight (kg) & $57 \cdot 3$ & 11.5 & $57 \cdot 3$ & $5 \cdot 2$ & $57 \cdot 4$ & $15 \cdot 9$ & $60 \cdot 9$ & $15 \cdot 9$ & 55.5 & 8.9 \\
\hline Mother's height $(\mathrm{cm})$ & $149 \cdot 2$ & 4.8 & 150.5 & 3.5 & $147 \cdot 8$ & $5 \cdot 7$ & $150 \cdot 8$ & 6.6 & $148 \cdot 4$ & 3.7 \\
\hline Mother's BMI $\left(\mathrm{kg} / \mathrm{m}^{2}\right)$ & $25 \cdot 6$ & 4.5 & $25 \cdot 3$ & $2 \cdot 8$ & $26 \cdot 0$ & 5.9 & $26 \cdot 6$ & $5 \cdot 6$ & $25 \cdot 2$ & $4 \cdot 1$ \\
\hline Infant's weight $(\mathrm{kg})$ & 6.5 & 0.9 & $6 \cdot 0$ & 0.4 & 7.0 & 1.1 & 6.4 & 0.5 & 6.5 & $1 \cdot 1$ \\
\hline Infant's length (cm) & $61 \cdot 7$ & 3.5 & 59.4 & 1.6 & $64 \cdot 0$ & $3 \cdot 4$ & $61 \cdot 3$ & 1.7 & 61.9 & $4 \cdot 2$ \\
\hline Infant's BMI (kg/m²) & $16 \cdot 9$ & 0.9 & $16 \cdot 9$ & 0.8 & $16 \cdot 9$ & 1.0 & $17 \cdot 1$ & 0.7 & $16 \cdot 9$ & $1 \cdot 0$ \\
\hline Weight/length $z$ score & 0.2 & 0.7 & 0.3 & 0.7 & 0.0 & 0.8 & 0.4 & 0.5 & $0 \cdot 1$ & 0.8 \\
\hline Length/age $z$ score & -0.6 & 0.9 & -0.3 & 0.7 & -0.8 & $1 \cdot 1$ & -0.4 & 0.5 & -0.69 & $1 \cdot 1$ \\
\hline Weight/age $z$ score & -0.3 & 0.9 & -0.03 & 0.6 & -0.6 & 1.1 & -0.02 & 0.5 & -0.47 & 1.07 \\
\hline BMI/age $z$ score & 0.04 & 0.7 & 0.23 & 0.6 & -0.15 & 0.8 & 0.28 & 0.5 & -0.09 & 0.77 \\
\hline
\end{tabular}

(Mean values and standard deviations) 
A moderate positive association was found between human milk intake and weight-for-length $z$ score, $r 0.58(P=0.01)$, BMI-for-age $z$ score, $r 0.56(P=0.01)$, and weight-for-age $z$ score, $r 0.45(P=0.05)$ as shown in Fig. 3. There was no correlation between human milk intake and LAZ, as shown in Fig. 2-3. No associations were found between infant size and intake of water from non-human milk sources.

\section{Lipid content of human milk}

The lipid content in human milk measured by creamatocrit was 41 (sD 12) g/l. There was no significant difference between age groups and sex. No associations were found between infant size and lipid content of human milk.

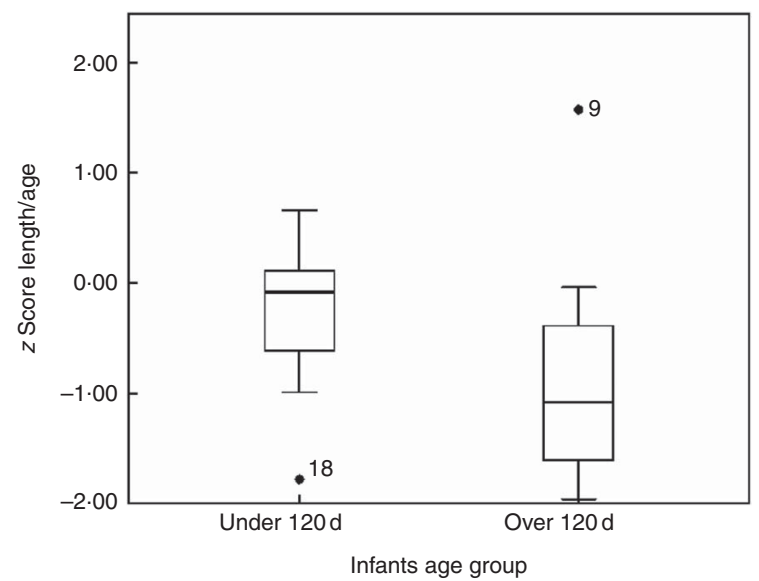

Fig. 2. Example of curves of ${ }^{2} \mathrm{H}$ enrichment in saliva from a mother-infant pair.
The energy content of human milk by creamatocrit was $3053.48 \quad(\mathrm{sD} \quad 524.25) \mathrm{kJ} / \mathrm{l} \quad(729 \cdot 8 \quad(\mathrm{sD} \quad 125 \cdot 3) \mathrm{kcal} / \mathrm{l})$. Considering the average milk intake was $888 \mathrm{ml} / \mathrm{d}$, the energy intake from human milk was 2681.94 (sD 464.42) kJ/d (641 (sD 111) kcal/d), which is adequate for infants of this age ${ }^{(15)}$.

\section{Discussion}

The inability to assess human milk intake directly has long been a challenge for nutrition researchers. Estimated nutrient requirements are based on human milk intakes combined with human milk composition, yet objective data on actual human milk intake remain sparse ${ }^{(23)}$.

Human milk intake was evaluated for the first time in breast-fed infants between 2 and 6 months of age in Bolivia at $3600 \mathrm{~m}$ above sea level. The intake of human milk in the present study is within the ranges published at the 9th International Breastfeeding Symposium $(478-1356 \mathrm{ml} / \mathrm{d})^{(24)}$, and similar to the WHO estimation for developing countries ${ }^{(25)}$

A positive relationship was found between the amount of human milk consumed and the infants' size, based on weightrelated indices, which is comparable with other studies. Similar to Brazil, Malawi and Senegal, we found positive associations between the human milk intake and infant's anthropometric indices, with weight-for-length $z$ score and weight-for-age $z$ score, but no association with $\operatorname{LAZ}^{(9,26,27)}$.

An approximation of energy content and lipid content can be performed by creamatocrit ${ }^{(10,27-30)}$. In this study, the range of lipid content is between 20 and $67 \mathrm{~g} / 1$, mainly owing to the variations during the day and during lactation ${ }^{(30-32)}$; we tried to minimise this effect by taking the samples at three times of the

Table 2. Human milk intake and non-breast-milk liquid intake

(Mean values and standard deviations)

\begin{tabular}{|c|c|c|c|c|c|c|c|c|c|c|}
\hline & \multicolumn{2}{|c|}{ Total $(n 18)$} & \multicolumn{4}{|c|}{ Groups by infant's age ( $\leq 120 \mathrm{~d}, n 9>120 \mathrm{~d}, n 9)$} & \multicolumn{4}{|c|}{ Groups by infant's sex (female, $n 6$; male, $n$ 12) } \\
\hline & Mean & SD & Mean & SD & Mean & SD & Mean & SD & Mean & SD \\
\hline Breast milk intake $(\mathrm{ml} / \mathrm{d})$ & $888 \cdot 0$ & $149 \cdot 6$ & $899 \cdot 3$ & $160 \cdot 9$ & $876 \cdot 7$ & $146 \cdot 2$ & $906 \cdot 2$ & $118 \cdot 9$ & 878.9 & $167 \cdot 0$ \\
\hline Water from other sources $(\mathrm{ml} / \mathrm{d})$ & $24 \cdot 3$ & $29 \cdot 8$ & $25 \cdot 4$ & $29 \cdot 9$ & $23 \cdot 2$ & 31.4 & $15 \cdot 0$ & 21.4 & $29 \cdot 0$ & $33 \cdot 0$ \\
\hline Total error $(\mathrm{mg} / \mathrm{kg})$ & $31 \cdot 3$ & $12 \cdot 2$ & $26 \cdot 8$ & $5 \cdot 2$ & $35 \cdot 8$ & $15 \cdot 7$ & $34 \cdot 2$ & $18 \cdot 16$ & $29 \cdot 9$ & $8 \cdot 6$ \\
\hline
\end{tabular}

(a)

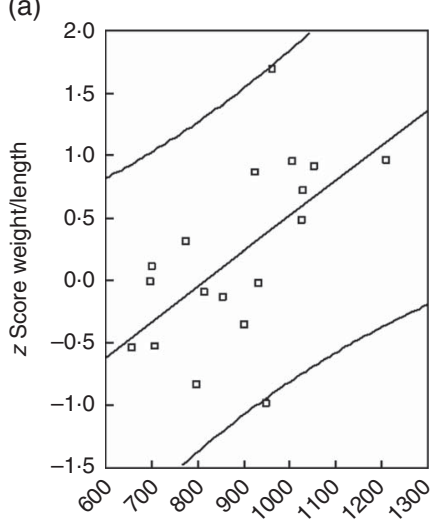

(b)

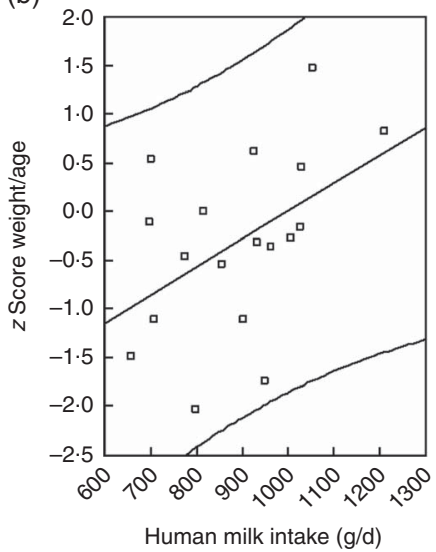

(c)

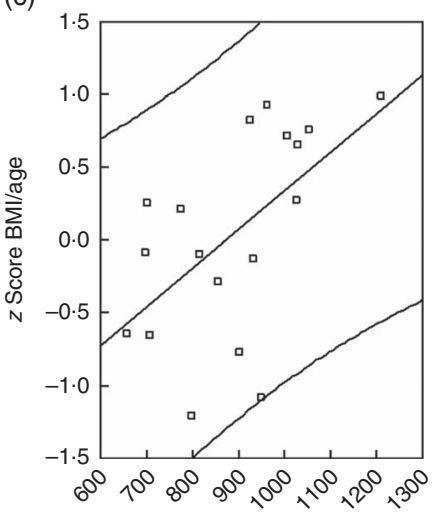

Fig. 3. Scatter plots to illustrate the relationships between nutritional indicators and human milk intake. (a) Weight-for-length z score, (b) weight-for-age z score and (c) BMI-for-age z score. 
day, analysing samples twice and by mixing samples to obtain averages over $24 \mathrm{~h}$. Our results are close to the 'normal' lipid content ranges reported from 35 to $45 \mathrm{~g} / \mathrm{l}^{(33-35)}$. The mean is similar to Lucas' study average of 40 (SD $4 \cdot 2) \mathrm{g} / \mathrm{l}^{(10)}$. According to the WHO (2002), the energy content of human milk varies between 2514.58 and $3242.6 \mathrm{~kJ} / 1$ (601 and $775 \mathrm{kcal} / \mathrm{l})$, with a mean of $2715.42 \mathrm{~kJ} / \mathrm{l}(649 \mathrm{kcal} / \mathrm{l})^{(25)}$. Our results are within this range, but taking the average human milk intake from this study $(888 \mathrm{ml} / \mathrm{d})$ together with the WHO mean energy content, the energy intake would be $2409.98 \mathrm{~kJ} / \mathrm{d}(576 \mathrm{kcal} / \mathrm{d})$. The energy requirement for breast-fed infants aged 3 months is $376.56 \mathrm{~kJ} / \mathrm{kg}$ per $\mathrm{d}(90 \mathrm{kcal} / \mathrm{kg} \text { per } \mathrm{d})^{(15)}$. For an infant weighing $6.5 \mathrm{~kg}$ (the mean in this study), the daily energy requirement is $2447.64 \mathrm{~kJ} / \mathrm{d}(585 \mathrm{kcal} / \mathrm{d})$. The energy content estimated using the creamatocrit, in average, would be sufficient to meet the infant's requirements recommended by the FAO. The energy requirements of infants living in less than ideal conditions in low- and middle-income countries need further investigation $^{(15)}$.

In this study, linear growth faltering was apparent in the older infants $(>120 \mathrm{~d})$. This tendency has been described earlier in infants from Bolivia; in a retrospective study using data from infant growth charts, infants at 4 months of age showed signs of stunting ${ }^{(36)}$. In the 1990 s, a randomised trial in developing countries evaluated early complementary food intake by 4-month-old breast-fed infants. In Bolivia, there was no effect on stunting. Even in the control group, the LAZ went from -1.0 at 4 months to -1.5 at 7 months ${ }^{(16)}$. Stunting is a sign of cumulative deficiencies in health and nutrition of a child long term.

Globally, massive growth faltering is observed in all five regions, although its magnitude differs by region. In Europe and Central Asia, mean LAZ values are close to the standard until 12 months, drop by $-0.05 z$ score per month in the 2 nd year and remain nearly stable thereafter. In Latin America and the Caribbean, very similar faltering patterns have been observed with average declines of -0.04 and $-0.06 z$ score per month, respectively, in the 1st year of life, and of -0.05 and -0.07 in the 2nd year. Children in both regions remain practically stable from ages 2 to 4 years. In Bolivia, these variations are remarkable ${ }^{(17)}$.

We hypothesise that growth faltering in Bolivian infants older than 4 months, who are receiving adequate human milk intake, is related to adverse living conditions, and exposure to environmental stressors. It has been shown that all known nutritional interventions combined, at $90 \%$ coverage, only amount to partial (one-third) reduction in stunting rates ${ }^{(37)}$. The influence of environmental factors, including living in unsanitary conditions, exposure to persistent organic pollutants, heavy metals and microbial toxins, is yet to be fully understood, but may induce environmental enteric dysfunction, which is a topic requiring further research ${ }^{(38,39)}$.

\section{Conclusion}

The amount and energy content of human milk is sufficient for the requirements of exclusively breast-fed infants in Bolivia in the first 4 months, but growth faltering that started to appear after this age suggests exposure to stressors that requires further investigation.

\section{Acknowledgements}

The authors thank the women who participated in the study, the valuable contributions of Instituto de Investigación en Salud y Desarrollo's (IINSAD) staff and the Division of Human Health, and Technical Cooperation Programme of the International Atomic Energy Agency, for the training courses and expert support to develop the isotopic technique.

This research received no specific grant from any funding agency, commercial or not-for-profit sectors. This research receives contributions of IINSAD's staff and the International Atomic Energy Agency for the training courses and expert support to develop the isotopic technique.

The authors' contributions were as follows: N. U. and J. L. S. M. formulated the research question and designed the study; N. U., J. L. S. M. and A. M. A. performed data collection; N. U. and M. M. performed ${ }^{2} \mathrm{H}$ dose-to-mother technique and enrichment analysis on FTIR; C. S. provided technical guidance on the use of the stable isotope technique and made corrections to the English language; N. U. performed statistical analysis, and wrote the first drafts of the manuscript. All of the authors contributed substantially, reviewed the manuscript and approved the final manuscript.

There are no competing financial interests in relation to the work described.

\section{References}

1. Hamosh M (2001) Bioactive factors in human milk. Pediatr Clin North Am 48, 69-86.

2. Dewey KG (2001) Nutrition, growth, and complementary feeding of the breastfed infant. Pediatr Clin North Am $\mathbf{4 8}$, 87-104.

3. Heinig MJ (2001) Host defense benefits of breastfeeding for the infant: Effect of breastfeeding duration and exclusivity. Pediatr Clin North Am 48, 105-123.

4. Davis MK (2001) Breastfeeding and chronic disease in childhood and adolescence. Pediatr Clin North Am 48, 125-141.

5. World Health Organization (2003) Estrategia mundial para la alimentación del lactante y del niño pequeño. (Global Strategy for Feeding of the Infant and Small Child). Geneva: WHO.

6. Butte NF, Wong W, Patterson BW, et al. (1988) Human-milk intake measured by administration of deuterium oxide to the mother: a comparison with the test-weighing technique. $A m J$ Clin Nutr 47, 815-821.

7. Coward WA, Whitehead RG, Sawyer MB, et al. (1979) New method for measuring milk intakes in breast-fed babies. Lancet 314, 13-14.

8. International Atomic Energy Agency (IAEA) (2010) Human Health Series to Assess Intake of Human Milk in Breastfed Infants. IAEA Human Health. Series, no. 7. Vol. 81. Vienna: IAEA.

9. Haisma H, Coward WA, Albernaz E, et al. (2003) Breast milk and energy intake in exclusively, predominantly, and partially breast-fed infants. Eur J Clin Nutr 57, 1633-1642.

10. Lucas A, Gibbs JA, Lyster RL, et al. (1978) Creamatocrit: simple clinical technique for estimating fat concentration and energy value of human milk. Br Med J 1, 1018-1020.

11. Ballard O \& Morrow AL (2013) Human milk composition. Nutrients and bioactive factors. Pediatr Clin North Am 60, 49-74.

12. Ministerio de Salud y Deportes de Bolivia (2008) Encuesta Nacional de Demografía y Salud (Health and Sports Ministry of Bolivia. 2008 Demographic and Health 
National Survey). http://www.dhsprogram.com/pubs/pdf/ FR228/FR228\%5B08Feb2010\%5D.pdf (accessed June 2012).

13. Lutter C (2012) World breastfeeding week 2012, Pan American Health Organization. http://www.paho.org/hq/ index.php?option $=$ com_docman\&task $=$ doc_download\&gid $=$ 18329\&Itemid $=270$ (accessed December 2013).

14. Reilly JJ, Ashworth S \& Wells JCK (2005) Metabolisable energy consumption in the exclusively breast-fed infant aged 3-6 months from the developed world: a systematic review. Br J Nutr 94, 56-63.

15. Food and Agriculture Organization/World Health Organization/United Nations University (2004) Human energy requirements. Report of a Joint $\mathrm{FAO} / \mathrm{WHO} / \mathrm{UNU}$ Expert Consultation: Rome, 17-24 October 2001. FAO Food Nutr Tech Rep Ser 103, 11-18

16. Simondon KB, Gartner A, Berger J, et al. (1996) Effect of early, short-term supplementation on weight and linear growth of 4-7 mo-old infants in developing countries: a four-country randomized trial. Am I Clin Nutr 64, 537-545.

17. Victora CG, de Onis M, Hallal PC, et al. (2010) Worldwide timing of growth faltering: revisiting implications for interventions. Pediatrics 125, e473-e480.

18. Slater C (2015) Guidance notes on evaluation of data in the Excel spreadsheet to calculate human milk intake by breastfed infants. Unofficial note AIEA. https://humanhealth.iaea.org/HHW/ Nutrition/MilkIntake/Draft_Guidance_notes_on_evaluation_of data_in_the_Excel_spreadsheet_06_Feb_2015_English_docx.pdf (accessed May 2017).

19. Neville MC (1995) Sampling and storage of human milk. In The Handbook of Milk Composition, pp. 63-78 [RG Jensen, editor]. San Diego, CA: Academic Press.

20. Organización Mundial de la Salud (2015) Obesidad y sobrepeso (Obesity and overweight). 311, 1-4. http://www.who. int/mediacentre/factsheets/fs311/es/ (accessed April 2017).

21. Mazariegos M, Slater C \& Ramirez-Zea M (2016) Validity of Guatemalan Mother's Self-reported breast-feeding practices of 3-month-old infants. Food Nutr Bull 37, 494-503.

22. Medoua GN, et al. (2012) Breastfeeding practices of Cameroonian mothers determined by dietary recall since birth and the dose-to-the-mother deuterium-oxide turnover technique. Matern Child Nutr 8, 330-339.

23. da Costa T, Haisma H, Wells J, et al. (2010) How much human milk do infants consume? Data from 12 countries using a standardized stable isotope methodology. J Nutr 140, 2227-2232.

24. Kent JC (2006) Volume and frequency of breastfeedings and fat content of breast milk throughout the day. Pediatrics 117, e387-e395.

25. Butte N, Lopez-Alarcon M \& Garza C (2002) Nutrient Adequacy of Exclusive Breastfeeding for the Term Infant During the First Six Months of Life. Geneva. WHO. http://www.who. int/nutrition/publications/infantfeeding/9241562110/en/index. html (accessed April 2014).

26. Galpin L, Thakwalakwa C, Phuka J, et al. (2007) Breast milk intake is not reduced more by the introduction of energy dense complementary food than by typical infant porridge. J Nutr 137, 1828-1833.

27. Agne-Djigo A, Kwadjode KM, Idohou-Dossou N, et al. (2013) Energy intake from human milk covers the requirement of 6-month-old Senegalese exclusively breast-fed infants. $\mathrm{Br} \mathrm{J}$ Nutr 110, 1849-1855.

28. Wang CD, Chu PS, Mellen BG, et al. (1999) Creamatocrit and the nutrient composition of human milk. J Perinatol 19, 343-346.

29. Kociszewska-Najman B, et al. (2012) The creamatocrit, fat and energy concentration in human milk produced by mothers of preterm and term infants. J Matern Neonatal Med 25 , $1599-1602$

30. Mitoulas L, Kent JC, Cox DB, et al. (2002) Variation in fat, lactose and protein in human milk over $24 \mathrm{~h}$ and throughout the first year of lactation. Br J Nutr 88, 29-37.

31. Macías S, Rodríguez S \& Ronayne de Ferrer P (2006) Leche materna: composición y factores condicionantes de la lactancia (Human milk: composition and conditional factors of breastfeeding). Arch Argent Pediatr 104, 423-430.

32. McClellan HL, Miller SJ \& Hartmann PE (2008) Evolution of lactation: nutrition $v$. protection with special reference to five mammalian species. Nutr Res Rev 21, 97-116.

33. García-López R (2011) Composición e inmunología de la leche humana (Composition and immunology of human milk). Acta Pediatr Mex 32, 223-230.

34. Jensen RG (1999) Lipids in human milk. Lipids 34, 1243-1271.

35. Koletzko B (2017) Human milk lipids. Ann Nutr Metab 69 , $28-40$.

36. Tapia W, San Miguel JL, Urteaga N, et al. (2014) Curvas de crecimiento infantil para detectar precozmente la talla baja en el menor de 2 años (Child growth curves for early detection of stunting in children under 2 years of age). Cuad Hosp Clin $\mathbf{5 5}$, 13-23.

37. Bhutta ZA, Ahmed T, Black RE, et al. (2008) What works? Interventions for maternal and child undernutrition and survival. Lancet 371, 417-440.

38. Keusch GT, Rosenberg IH, Denno DM, et al. (2013) Implications of acquired environmental enteric dysfunction for growth and stunting in infants and children living in low- and middle-income countries. Food Nutr Bull 34, 357-364.

39. Mbuya MN \& Humphrey JH (2015) Preventing environmental enteric dysfunction through improved water, sanitation and hygiene: an opportunity for stunting reduction in developing countries. Matern Child Nutr 12, Suppl. 1, 106-120. 